\title{
Intervention strategies for the reduction of microbiological contamination on the hands of food handlers
}

\author{
Naína Lopes de JESUS ${ }^{1}$, Ana Lúcia SERAFIM², Laissa Benites MEDEIROS³, Caroline dos Santos PEIXOTO, \\ Lize STANGARLIN-FIORI ${ }^{5,6 *}$
}

\begin{abstract}
The purpose of this study was to evaluate intervention strategies for the reduction of microbiological contamination on the hands of food handlers. The study was conducted from January 2009 to December 2014 at a food and nutrition company in Curitiba, Brazil. Samples from the hands of 877 handlers were collected for microbiological analysis. The intervention strategies applied during each year were: 2009, substitute the use of odorless liquid soap and an antiseptic product by one product; 2010, was increasing the staff of technical supervisors and conducting biannual training; 2011 was to move the lavatories for handwashing, and the use of $70 \%$ alcohol gel; 2012, was to increase the frequency of the training of food handlers; 2013, was new weekly monitoring, to evaluation of the use of bactericide soap; 2013 and 2014 was implemented an internal program to verify food production. The intervention introduced in 2011 the 2012 and 2013 the 2014 reduced the contamination of the hands of food handlers. The use of $70 \%$ alcohol gel, the moving of the location of the lavatories, weekly monitoring of the use of bactericide soap and implementation of the internal program, were the strategies that contributed the most to the reduction of the microbial.
\end{abstract}

Keywords: quality control; hand; foodborne diseases; food hygiene; food inspection.

Practical Application: Reduction of the microbial load in the hands of handlers after intervention strategies. Moving of the lavatories reduced the contamination of the hands of handlers. Monitoring of the use of bactericide soap reduced the contamination of the hands of handlers. Implementation of the internal program reduced the contamination of the hands of handlers.

\section{Introduction}

The contamination of the hands of food handlers has been identified as one of the factors that contributes to the increase of foodborne disease outbreaks identified at food establishments (Gould et al., 2013). Microorganisms can be transferred to foods by the hands, forming enterotoxins, which can cause acute gastroenteritis when ingested (Ho et al., 2015).

Various studies have reported the occurrence of foodborne disease outbreaks, which were attributed to the absence of proper handwashing. In 2011 in the United States, an outbreak involving Escherichia coli O157:H7 in which one person died and twelve people became ill was attributed to improper handwashing (Herzog, 2011). Todd et al. (2008), analyzed 816 foodborne outbreaks and found that improper handwashing played a large role in the outbreaks.

Proper handwashing during food preparation is an effective and simple strategy for reducing crossed contamination and preventing foodborne outbreaks (Pellegrino et al., 2015), and is recognized as an important public health measure (Best et al., 2014). Despite national and international recommendations about handwashing, compliance with this procedure continues to be insufficient (Scheithauer \& Lemmen, 2013).

Handwashing involves two steps, the cleaning and sanitizing of hands. Cleaning is the step of washing the hands with potable water, and drying with a paper towel or other safe method, while sanitizing involves the application of an antiseptic product to reduce and or inhibit microbial growth, which should be conducted after the cleaning step (Food and Drug Administration, 2013). The frequency of handwashing is also important for prevention of foodborne disease (Pragle et al., 2007), and should be conducted before handling foods, after any work interruption, after touching contaminated materials, after using the bathroom and whenever necessary (Brasil, 2004).

It should be emphasized that various factors can contribute to the absence of suitable handwashing at food establishments, among which stand out the absence of commitment of administrators and food handlers, lack of time, insufficient education and lack of suitable investments (Howells et al., 2008). 
In this sense, it is up to food establishments to provide all the resources needed for handwashing, such as an exclusive lavatory for handwashing, odorless, antiseptic liquid soap, or odorless liquid soap and an antiseptic product, new paper towels or another safe and hygienic system for hand drying, and a waste bin with a lid that can be opened without manual contact (Brasil, 2004).

According to Prado et al. (2015), people say that they understand the importance of handwashing but in many cases do not conduct the procedure frequently and do so incorrectly. Changes in the behavior of individuals, including handwashing are difficult to achieve (Ali et al., 2014), which reinforces the importance of using intervention strategies that can help correct these procedures (Çakıroğlu \& Uçar, 2008).

The intervention strategies should be conducted regularly, because they influence the proper realization of the procedure (Serafim et al., 2015). Nevertheless, studies reveal that increased knowledge does not always lead to a significant change in behavior in washing procedures during the work routine (Grintzali \& Babatsikou, 2010; Sung-Hee et al., 2010). The intervention strategies to be efficient should lead to changes in awareness, commitment and behavior in work processes (Serafim et al., 2015).

Thus, this study aimed to evaluate the intervention strategies for the reduction of microbiological contamination of the hands of food handlers.

\section{Methodology}

A descriptive and transversal study was conducted from January 2009 to December 2014 at a private food and nutrition company that produces transported meals, located in the city of Curitiba, Paraná (PR), Brazil and chosen because of convenience and criteria of access. The company produced an average of 250 thousand meals per day, supplying pre-schools, elementary schools and youth and adult education programs, prisons and companies in Curitiba and the metropolitan region.

The study population was defined as all the individuals working in food preparation areas during three shifts (morning, afternoon and night), who are denominated as food handlers in the study. As the company had an average of 150 employees per year in the areas of food preparation were evaluated annually at least 109 hands of food handlers, to a sampling error of $5 \%$, amounting to a total sample of 877 handlers. The food handlers were chosen at random from the various processing areas and work shifts, selecting those who were available to participate in the study and who signed the Free, prior and Informed Consent Agreement (FPIC).

The collection of samples for microbiological analyses of the hands of the food handlers were conducted monthly, from January 2009-December 2014, using the swab technique, proposed by the Compendium of methods for the microbiological examination of foods (Midura \& Bryant, 2001).

Samples were collected in two moments with each handler. The first Samples was collected while the handlers were doing their routine work, without requesting that they wash their hands. And the second collection was performed after the food handlers considered their hands to be clean. The handwashing was conducted in lavatories exclusively for this purpose, with antiseptic soap approved by the Ministry of Health, non-recycled paper towels, waste bins operated without manual contact and with a poster on display explaining the correct handwashing procedure. The handwashing procedure was conducted by the food handler without interference and with technical supervision to verify the procedure.

\section{Data collection}

The collection of the swabs from the hands of the food handlers, as well as their analyses, were conducted by a sub-contracted microbiology laboratory. Microbiological analyses were performed on samples collected with sterile swabs (mark INLAB), each individually packed with a flexible plastic rod polystyrene (PS) and 15-cm-long cotton tip. To collect a hand sample, the swab was soaked in phosphate-buffered saline solution and then rubbed on both hands, in all the areas, at the edges of the fingers and nails, backs and palms. The swabs were transferred to test tubes containing $10 \mathrm{ml}$ of phosphate-buffered saline solution and the analyses were performed according to the procedure recommended by the methodology proposed by the Compendium of methods for the microbiological examination of foods (Midura \& Bryant, 2001), to give $10^{-1}$ dilution, and from this, the successive decimal dilutions up to $10^{-3}$ were prepared. All analyzes were performed in triplicate.

Analysis was conducted for the most probable number of thermotolerant coliform and the results were expressed as contaminated hands, when the limits found in the analyses were above $0.4 \log \mathrm{NMP} / \mathrm{mL}$ (Balzaretti \& Marzano, 2013). The samples were collected one year to test the effective implementation of the each new strategy.

The intervention strategies applied during each year of the study: in 2009, was substitute the use of odorless liquid soap and an antiseptic product by only one product that had the two functions, this being antiseptic soap; in 2010, was increasing the staff of technical supervisors and conducting biannual training of food handlers, reinforcing the principles of good hygiene/handwashing; in 2011 was to move the exclusive lavatories for handwashing to the food preparation areas, and $70 \%$ alcohol gel was placed at the lavatories, together with antiseptic soap; in 2012, was to increase the frequency of the training of food handlers from every six months to every three months to attain more efficient handwashing; in 2013, was new weekly monitoring, in which the supervisors kept records of the use of bactericide soap and $70 \%$ alcohol gel at the different production areas of the company, by checking the frequency of the refilling of the soap dispensers; in 2013 and 2014 an internal program was implemented at the company to measure and verify the effectiveness of the good manufacturing practices and management of food production areas. This program was applied by the Department of Quality, with weekly evaluation of two requisites; the security risk of the foods and client satisfaction. 


\subsection{Statistical analysis}

The data were analyzed through simple descriptive statistics (media and percentages). The results were analyzed by means of the index of growth, rate of growth and rate of mean growth, being the percentage calculated yearly, that is, number of hands contaminated ${ }^{\star} 100$. In order to verify differences between proportions, that is, the proportion of hands contaminated per year, Z test was used to compare two proportions and the Spearman correlation coefficient, all with significance level of $5 \%$, making use of the SAS ${ }^{\circledast}$ Software (Statistical Analysis System), version 9.2.

\section{Results and discussion}

The results below demonstrate the intervention strategies used over the years for the purpose of reduced microbiological contamination of the hands of food handlers.

Table 1 demonstrates the results of the microbiological analyses conducted on the hands of food handlers at the company evaluated.

It was found that during the six years of the study, $13.0 \%$ of the food handlers had contaminated hands in the first collection, while $2.9 \%$ remained contaminated after handwashing (Table 1). The higher contamination, found in the first collection, suggests that these handlers did not wash their hands properly, before or during the steps of food preparation. It can also be related to the handling of raw foods, which had still not undergone processes to reduce their initial microbial load, or to contact with contaminated equipment and utensils, which may have generated crossed contamination.

Pellegrino et al. (2015) reveal that in the food preparation steps, the greatest risk of contamination of hands occurs during the handling of raw foods, or that is, those foods that do not undergo any process capable of to reducing the initial microbial load, which can cause crossed contamination, placing at risk the safety of foods ready for consumption. Corroborating with this, Phang \& Bruhn (2011), also found in their study that the hands of the food handlers were the vehicle with the highest possibilities for cross contamination during the work routine. This may be justified by the fact that the contamination of the hands of food handlers is one of the factors found by studies to make the greatest contribution to foodborne disease outbreaks (Todd et al., 2010).

In the year of 2011 it was registered the biggest number of contaminated hands, from which $23.8 \%(n=46)$ presented being contaminated on first collection, while $4.1 \%$ stayed contaminated even after hand sanitation (Table 1). This study can be related to the occurrence in the company, this year, of an increase in the production of meals, without altering the number of employees, that is, the workforce did not keep up with the production growth, resulting in a work overload to the company's employees, making them prioritize activities that they deemed more important.

A study carried out by Cunha et al. (2014), also reveal that the number of meals prepared by manipulators can have a negative effect over adequate hygiene practices. According to the same authors, the bigger the number of meals prepared by the food manipulator, the lower will be the number of hygienic and sanitary procedures realized, as overloaded food manipulators may neglect correct procedures, favoring practices that ease or accelerate the production of meals.

In 2009 (Table 1), it was found that $1.9 \%$ of the hands analyzed in the second collection continued to be contaminated. In this year, the strategy used to reduce the microbial load was to substitute the use of liquid soap and an antiseptic product by only one product that had the two functions, this being antiseptic soap. This strategy was implemented, because the hand contamination could be related to the use of only liquid soap, by food handlers, during handwashing, forgetting to use the antiseptic product.

The cleaning refers to the physical or mechanical removal of mineral or organic impurities such as dirt, fat, dust, and others (Brasil, 2004), does not show an effective method for reducing microorganisms. Therefore, the cleaning should be conducted frequently and complemented by hand sanitizing, with antiseptic product (Ho et al., 2015).

This hypothesis was discarded the following year, in 2010, because the percentage of contaminated hands increased $0.4 \%$ in the first collection and $0.2 \%$ in the second collection (Table 2). In this year the intervention strategies applied included increasing

Table 1. Contamination of the hands of manipulators, between the years of implementation of intervention strategies, in the first and second collection, held in the power unit and private nutrition that produces transported meals, Curitiba, Brazil, 2009-2014.

\begin{tabular}{|c|c|c|c|c|c|c|}
\hline & \multicolumn{2}{|c|}{ Collections } & \multicolumn{4}{|c|}{ hand contamination } \\
\hline & \multirow{2}{*}{$\frac{\text { First }}{\text { (n) }}$} & \multirow{2}{*}{$\begin{array}{c}\text { Second } \\
(\mathrm{n})\end{array}$} & \multicolumn{2}{|c|}{ First } & \multicolumn{2}{|c|}{ Second } \\
\hline & & & (n) & $(\%)$ & (n) & $(\%)$ \\
\hline 2009 & 109 & 109 & 9 & 8.7 & 2 & 1.9 \\
\hline 2010 & 128 & 128 & 16 & 12.5 & 3 & 2.3 \\
\hline 2011 & 193 & 193 & 46 & 23.8 & 8 & 4.1 \\
\hline 2012 & 186 & 186 & 14 & 7.5 & 4 & 2.1 \\
\hline 2013 & 140 & 140 & 19 & 13.5 & 5 & 3.5 \\
\hline 2014 & 121 & 121 & 10 & 8.2 & 4 & 3.3 \\
\hline Total & 877 & 877 & 114 & 13.0 & 26 & 2.9 \\
\hline
\end{tabular}

Key: n: number of samples; \%: percentage; First: refers to the initial collection, conducted while the food handlers were working, without requesting that their hands be washed. Second: refers to the collection conducted after the handlers washed their hands and considered them to be clean. 
Table 2. Annual rate growth of microbiological contamination of the hands of manipulators, and significant statistical difference, between the years of implementation of intervention strategies in the first and second collection, held in the power unit and private nutrition that produces transported meals, Curitiba, Brazil, 2009-2014.

\begin{tabular}{crlrc}
\hline \multirow{2}{*}{ Comparing the years } & \multicolumn{3}{c}{ Comparative test } \\
\cline { 2 - 5 } & First & p-value & Second & $0.2 \%$ \\
2009-2010 & $0.4 \%$ & 0.3603 & $0.5 \%$ & 0.8347 \\
$2010-2011$ & $0.3 \%$ & $0.0118^{*}$ & $-0.7 \%$ & 0.3850 \\
$2011-2012$ & $-0.8 \%$ & $0.0001^{*}$ & $2.2 \%$ & 0.2676 \\
$2012-2013$ & $4.7 \%$ & 0.0733 & $-0.4 \%$ & 0.4383 \\
$2013-2014$ & $-0.7 \%$ & 0.1737 & 066 \\
\hline
\end{tabular}

Notes: First: refers to initial collection, conducted while food handlers were working, without requesting handwashing. Second: refers to collection conducted after the food handlers considered their hands washed and sanitized. $\mathrm{p}$-value: T-test for independent samples $(\mathrm{p}<0.05) .{ }^{*}$ : significant values.

the staff of technical supervisors and conducting biannual training of food handlers, reinforcing the principles of good hygiene/handwashing.

According to Vo et al. (2015), training for food handlers is of extreme importance, although if the supervision is not continuous the work will not be conducted efficiently. This affirmation is proven in the study by Samapundo et al. (2015), which found that $76 \%$ of the food handlers evaluated knew that handwashing is one of the practices that is sufficient for maintaining food quality, although without continuous supervision they wind up not conducting the correct procedures. Therefore, even if the handwashing procedures are proper, it is suggested that the food handlers be supervised during the routine activities, to guarantee their efficiency.

The application of new strategies supported by the scientific literature to increase the knowledge, awareness and commitment of handlers to the proper realization of handwashing was not sufficient for decreasing the microbial load in the following year, in 2011 (Table 2), when an increase in contaminated hands was found, in both the first collection $(0.3 \%)$, and in the second collection $(0.5 \%)$.

It should also be highlighted that in 2011, there was a significant increase $(\mathrm{p}=0.0118)$ in the number of contaminated hands in relation to 2010 (Table 2). This result was important in the re-evaluation of the actions that were being conducted at the company, and in this year the intervention strategy used was to move the exclusive lavatories for handwashing to the food preparation areas, and $70 \%$ alcohol gel was placed at the lavatories, together with antiseptic soap, which was implemented in the previous year, to complement the handwashing.

The alcohol-based products are considered one of the safest antiseptic products, and are broadly used at food establishments because of their effective action in the reduce of pathogenic microrganisms (Ji-Hyoung et al., 2016). Prado et al. (2015), found reduction of $99.6 \%$ of microbiota on the hands of food handlers after the use of ethyl alcohol 70\%.

The best bactericide effect of alcohol (ethanol) is obtained at a composition of 70\% (International Commission on Microbiological Specifications for Foods, 1991). The study by Holvoet et al. (2014) also found that the use of antiseptics such as $70 \%$ alcohol guarantee destruction of nearly all possible microorganisms present on the hands of food handlers, which reinforces the importance of their use to obtain even more desirable results in handwashing.

In 2012 (Table 2), a significant decrease was found ( $\mathrm{p}=0.0001$ ) in the number of contaminated hands in relation to 2011, and a reduction in the growth rate in both the first collection $(-0.8 \%)$ and in the second collection $(-0.7 \%)$ (Table 2$)$. These results demonstrate that the insertion of $70 \%$ alcohol gel was placed at the lavatories, together with antiseptic soap, which was implemented in the previous year, to complement the handwashing and the moving of the handwashing lavatories, may have contributed to decreasing the contamination found on the hands of food handlers.

The study by Zellmer et al. (2015), also revealed that the placement of lavatories where they can easily be seen helps to improve adhesion to handwashing. Therefore, maintaining products and physical infrastructure suitable to handwashing motivates food handlers to adopt the correct behavior and maintain hygienic conditions (Cunha et al., 2014).

In 2012, the intervention strategy applied in the study was to increase the frequency of the training of food handlers from every six months to every three months to attain more efficient handwashing. To avoid that the content passed on was forgotten by the food handlers, the training should be conducted frequently (Cunha et al., 2014). Brazil's national sanitary laws for food services (Brasil, 2004), do not specify a frequency for training food handlers, and only mention that training should be conducted periodically, which makes this requirement quite vulnerable and training is not commonly conducted.

It should be emphasized that the increased knowledge obteined after training results in a significant behavioral shift in the handwashing procedures conducted during the work routine (Sung-Hee et al., 2010). Efficient training, in addition to providing information, must lead to changes in awareness, commitment and behavior in the work processes. For this reason, the trainings should be planned, identifying the practices that need to be improved in relation to handwashing, so that the problem is addressed in the proper context and the changes are conducted (Pragle et al., 2007; Van Tonder et al., 2007).

In 2013, it was found that the strategies previously realized and the increased frequency of training were not sufficient to decrease the contamination of hands at the company evaluated, and there was an increase of $4.7 \%$ in the first collection and 
of $2.2 \%$ in the second collection in relation to 2012 (Table 2). Based on these results an intervention strategy was inserted in this year, new weekly monitoring, in which the supervisors kept records of the use of bactericide soap and 70\% alcohol gel at the different production areas of the company, by checking the frequency of the refilling of the soap dispensers. The purpose of this strategy was to identify problems with handwashing in each food preparation areas by evaluating the practices that needed greater attention.

The new weekly monitoring revealed that soap dispensers were not refilled in some of the company's production areas, revealing that the products were not being used correctly. These results indicated the need to intensify technical supervision in these specific areas, and weekly training was conducted in these food preparation areas.

In 2013, an internal program was implemented at the company to measure and verify the effectiveness of the good manufacturing practices and management of food production areas. This program was applied by the Department of Quality, with weekly evaluation of two requisites; the security of the foods and client satisfaction. The food production area that had the best performance in the reduction of contamination on the hands of food handlers, and the highest rate of client satisfaction, received a $5 \%$ salary bonus for 6 months, until a new evaluation was conducted.

In the last year of the study, in 2014, (Table 2), a decrease in hand contamination was found, both in the first collection $(-0.7 \%)$ and in the second $(-0.4 \%)$, when compared with the previous year (2013). These results demonstrate that the internal program implemented to evaluate the good manufacturing practices and management of the process may have helped to encourage the food handlers to meet the requirements for handwashing more efficiently.

The interventions applied in food establishments to reduce the microbial load on the hands requires an approach that involves the entire staff and the understanding of its requirements (Buccheri et al., 2007). These interventions should be constantly analyzed, to identify the potential weaknesses of the methods conducted and promote more effective procedures.

A study conducted in food establishments also revealed improvements after intervention strategy, suggesting that the companies adopt these programs in a continuous manner, because they help to motivate the work staff and thus lead to continuity in compliance with the good practices (Cunha et al., 2013).

\section{Conclusion}

The results of this study reveal that the intervention strategies introduced in 2011 the 2012 and 2013 the 2014 reduced the contamination of the hands of food handlers.

The use of $70 \%$ alcohol gel, in conjunction with antiseptic soap, the moving of the location of the lavatories for handwashing to the production areas, weekly monitoring, in which the supervisors kept records of the use of bactericide soap and 70\% alcohol gel and the implementation of the internal program for evaluation of good manufacturing practices and management of the process, were the strategies that contributed the most to the reduction of the microbial load, when compared by year.

The study also reinforces the importance of always seeking new interventions to identify the most adequate procedures, and to make food handlers aware of the importance of handwashing and develop their commitment to proper washing to decrease the risks of food contamination at food establishments associated to this procedure.

\section{References}

Ali, M. M., Verrill, L., \& Zhang, Y. (2014). Self reported hand was hing behaviors and foodborneillness: a propensity score matching approach. Journal of Food Protection, 77(3), 352-358. PMid:24674424. http://dx.doi.org/10.4315/0362-028X.JFP-13-286.

Balzaretti, C. M., \& Marzano, M. A. (2013). Prevention of travelrelated foodborne diseases: microbiological risk assessment of food handlers and ready-to-eat foods in northern Italy airport restaurants. Food Control, 29(1), 202-207. http://dx.doi.org/10.1016/j. foodcont.2012.05.077.

Best, E. L., Parnell, P., \& Wilcox, M. H. (2014). Microbiological comparison of hand-drying methods: the potential for contamination of the environment, user, and by stander. The Journal of Hospital Infection, 88(4), 199-206. PMid:25237036. http://dx.doi.org/10.1016/j. jhin.2014.08.002.

Brasil. Agência Nacional de Vigilância Sanitária. (2004, Setembro 15). Resolução - RDC no 216, de 15 de setembro de 2004. Dispõe sobre regulamento técnico de boas práticas para serviços de alimentação. Diário Oficial [da] República Federativa do Brasil, Poder Executivo.

Buccheri, C., Casuccio, A., Giammanco, S., Giammanco, M., La Guardia, M., \& Mammina, C. (2007). Food safety in hospital: knowledge, attitudes and practices of nursing staff of two hospitals in Sicily, Italy. Health Services Research, 7(45), 1-11. PMid:17407582.

Çakıroğlu, F. P., \& Uçar, A. (2008). Employees' perception of hygiene in the catering industry in Ankara (Turkey). Food Control, 19(1), 9-15. http://dx.doi.org/10.1016/j.foodcont.2007.01.001.

Cunha, D. T., Fiorotti, R. M., Baldasso, J. G., Sousa, M., Fontanezi, N. M., Caivano, S., Stedefeldt, E., Rosso, V. V., \& Camargo, M. C. R. (2013). Improvement of food safety in school meal service during a long-term intervention period: a strategy based on the knowledge, attitude and practice triad. Food Control, 34(2), 662-667. http:// dx.doi.org/10.1016/j.foodcont.2013.06.003.

Cunha, D. T., Stedefeldt, E., \& Rosso, V. V. (2014). The role of theoretical food safety training on Brazilian food handlers' knowledge, attitude and practice. Food Control, 43, 167-174. http://dx.doi.org/10.1016/j. foodcont.2014.03.012.

Food and Drug Administration. (2013). Food safety modernization act proposed rule for produce safety, standards for the growing, harvesting, packing, and holding of produce for human consumption (Corrected version). Food and Drug Administration, 21, 16-112.

Gould, L. H., Walsh, K. A., Vieira, A. R., Herman, K., Williams, I. T., Hall, A. J., \& Cole, D. (2013). Surveillance for Foodborne Disease Outbreaks-United States, 1998-2008. Morbidity and Mortality Weekly Report, 62(2), 1-34. PMid:23804024.

Grintzali, G. P., \& Babatsikou, F. (2010). The significance of the application of Hazard Analysis Critical Control Point System in hospital catering. Health Science Journal, 4(2), 84-93.

Herzog, K. (2011). Poorhand-washingledto green county E. coli outbreak. Retrieved from http://www.jsonline.com/features/health/poorhandwashing-led-to-green-county-ecoli-outbreak-132279498. html 
Ho, J., Boost, M. V., \& O’Donoghue, M. M. (2015). Tracking sources of Staphylococcus aureus hand contamination in food handlers by spa typing. American Journal of Infection Control, 43(7), 759-761. PMid:25997877. http://dx.doi.org/10.1016/j.ajic.2015.03.022.

Holvoet, K., Keuckelaere, A., Sampers, I., Van Haute, S., Stals, A., \& Uyttendaele, M. (2014). Quantitative study of cross-contamination with Escherichia coli, Escherichia coli O157, MS2 phage and murine norovirus in a simulated fresh-cut lettuce wash process. Food Control, 37, 218-227. http://dx.doi.org/10.1016/j.foodcont.2013.09.051.

Howells, A. D., Roberts, K. R., Shanklin, C. W., Pilling, V. K., Brannon, L. A., \& Barrett, B. B. (2008). Restaurant employees' perceptions of barriers to three food safety practices. Journal of the American Dietetic Association, 108(8), 1345-1349. PMid:18656574. http:// dx.doi.org/10.1016/j.jada.2008.05.010.

International Commission on Microbilogical Specifications for Foods. (1991). El sistema de analisis de riesgos y puntos críticos (pp. 77-109). Zaragoza: Acribia.

Ji-Hyoung, H., Changsun, C., Hee-Jung, L., In-Sun, J., Jeong-Su, L., \& Sang-Do, H. (2016). Efficacy of chemical disinfectant compounds against human norovirus. Food Control, 59, 524-529. http://dx.doi. org/10.1016/j.foodcont.2015.04.040.

Midura, T. F., \& Bryant, R. G. (2001). Sampling plants, sample collection, shipment, and preparation for analysis. In F. P. Downes \& K. Ito (Eds.), Compendium of methods for the microbiological examination offoods (4th ed., pp. 13-23). Washington: American Public Health Association.

Pellegrino, R., Crandall, P. G., \& Seo, H. S. (2015). Hand washing and disgust response to handling different food stimuli between two different cultures. Food Research International, 76(Part 2), 301-308. http://dx.doi.org/10.1016/j.foodres.2014.12.027.

Phang, H. S., \& Bruhn, C. M. (2011). Burger preparation: what consumers say and do in the home. Journal of Food Protection, 74(10), 1708-1716. PMid:22004819. http://dx.doi.org/10.4315/0362-028X.JFP-10-417.

Prado, D. B., Bettoni, A. P., Correa, V. A., Abreu, B. A. A., Fo, Garcia, L. B., Tognim, M. C. B., \& Cardoso, C. L. (2015). Practice of hand hygiene in a university dining facility. Food Control, 57(1), 35-40. http://dx.doi.org/10.1016/j.foodcont.2015.03.024.

Pragle, A. S., Harding, A. K., \& Mack, J. C. (2007). Food workers' perspectives on hand washing behaviors and barriers in the restaurant environment. Journal of Environmental Health, 69(10), 27-32. PMid:17583293.

Samapundo, S., Climat, R., Xhaferi, R., \& Devlieghere, F. (2015). Food safety knowledge, attitudes and practices of street food vendors and consumers in Port-au-Prince, Haiti. Food Control, 50, 457-466. http://dx.doi.org/10.1016/j.foodcont.2014.09.010.

Scheithauer, S., \& Lemmen, S. W. (2013). How can compliance with hand hygiene be improved inspecialized are as of a university hospital? The Journal of Hospital Infection, 83(S1, Suppl 1), S17-S22. PMid:23453171. http://dx.doi.org/10.1016/S0195-6701(13)60005-5.

Serafim, A. L., Hecktheuer, L. H. R., Stangarlin-Fiori, L., Medeiros, L. B., Martello, L., \& Machado, C. E. (2015). Evaluation of the implementation of good handling practices in food and beverage areas of hotels. Journal of Food Protection, 78(11), 2043-2051. PMid:26555528. http://dx.doi.org/10.4315/0362-028X.JFP-15-144.

Sung-Hee, P., Tong-Kyung, K., \& Hye-Ja, C. (2010). Evaluation of the food safety training for food handlers in restaurant operations. Nutrition Research and Practice, 4(1), 58-68. PMid:20198210. http:// dx.doi.org/10.4162/nrp.2010.4.1.58.

Todd, E. C., Greig, J. D., Bartleson, C. A., \& Michaels, B. S. (2008). Outbreaks where food workers have been implicated in the spread of food borne disease. Part 4: infective doses andpathogencarriage. Journal of Food Protection, 71(11), 2339-2373. PMid:19044283.

Todd, E. C., Michaels, B. S., Greig, J. D., Smith, D., Holah, J., \& Bartleson, C. A. (2010). Outbreaks where food workers have been implicated in the spread of food borne disease. Part 7: barriers to reduce contamination of food by workers. Journal of Food Protection, 73(8), 1552-1565. PMid:20819372.

Van Tonder, I., Lues, J. F., \& Theron, M. M. (2007). The personal and general hygiene practices of food handlers in the delicatessen sections of retail outlets in South Africa. Journal of Environmental Health, 70(4), 33-38. PMid:18044251.

Vo, T. H., Le, N. H., Le, A. T. N., Tran Minh, N. N. T., \& Nuorti, J. P. (2015). Knowledge, attitudes, practices and training needs of foodhandlers in large canteens in Southern Vietnam. Food Control, 57, 190-194. http://dx.doi.org/10.1016/j.foodcont.2015.03.042.

Zellmer, C., Blakney, R., Van Hoof, S., \& Safdar, N. (2015). Impact of sink location on hand hygiene compliance for Clostridium difficile infection. American Journal of Infection Control, 43(4), 387-389. PMid:25704256. http://dx.doi.org/10.1016/j.ajic.2014.12.016. 